\title{
Multidirectional Time-Dependent Effect of Sinigrin and Allyl Isothiocyanate on Metabolic Parameters in Rats
}

\author{
Monika Okulicz
}

Published online: 1 September 2010

(C) The Author(s) 2010. This article is published with open access at Springerlink.com

\begin{abstract}
Sinigrin (SIN) and allyl isothiocyanate (AITC) are compounds found in high concentrations in Brassica family vegetables, especially in Brussels sprouts. Recently, they have been used as a nutrition supplement for their preventive and medicinal effect on some types of cancer and other diseases. In this research, nutritional significance of parent glucosinolate sinigrin $50 \mu \mathrm{mol} / \mathrm{kg}$ b. w./day and its degradation product allyl isothiocyanate $25 \mu \mathrm{mol} / \mathrm{kg} \mathrm{b}$. w./day and $50 \mu \mathrm{mol} / \mathrm{kg} \mathrm{b}$. w. $/$ day was studied by the evaluation of their influence on some parameters of carbohydrate and lipid metabolism in an animal rat model in vivo after their single $(4 \mathrm{~h})$ and 2 weeks oral administration. Additionally, the aim of this trial was to evaluate the direct action of AITC on basal and epinephrineinduced lipolysis in isolated rat adipocytes at concentration $1 \mu \mathrm{M}, 10 \mu \mathrm{M}$ and $100 \mu \mathrm{M}$ in vitro. Sole AITC after $4 \mathrm{~h}$ of its ingestion caused liver triacylglycerols increment at both doses and glycaemia only at the higher dose. Multiple SIN treatment showed its putative bioconversion into AITC. It was found that SIN and AITC multiple administration in the same way strongly disturbed lipid and carbohydrate homeostasis, increasing esterified and total cholesterol, free fatty acids and lowering tracylglycerols in the blood serum. Additionally, AITC at both doses elevated insulinaemia and liver glycogen enhancement. The in vitro experiment revealed that AITC potentiated basal lipolysis process at $10 \mu \mathrm{M}$, and had stimulatory effect on epinephrine action at $1 \mu \mathrm{M}$ and $10 \mu \mathrm{M}$. The results of this study demonstrated that the effect of SIN and AITC is multidirectional, indicating its impact on many organs like liver as well as pancreas, intestine in vivo action and rat adipocytes in vitro. Whilst consumption of cruciferous
\end{abstract}

M. Okulicz $(\square)$

Department of Animal Physiology and Biochemistry;

Faculty of Animal Breeding and Biology,

University of Life Sciences in Poznań,

Wołyńska 35,

60-637 Poznań, Poland

e-mail: mokulicz@au.poznan.pl vegetables at levels currently considered "normal" seems to be beneficial to human health, this data suggest that any large increase in intake could conceivably lead to undesirable effect. This effect is potentiated with time of action of the examined compounds, whose influence is rather adverse for the majority of metabolic pathways (liver steatosis at short duration and insulinaemia, cholesterolaemia at long time treatment). Beneficial action of AITC concerned intensified hydrolysis of TG in the blood serum with a simultaneous lipolysis in adipocytes.

Keywords Adipocytes - Allyl isothiocyanate - Metabolism · Rat $\cdot$ Sinigrin

$\begin{array}{ll}\text { Abbrevations } \\ \text { ACAT } & \text { acyl-CoA:cholesterol acyltransferase } \\ \text { AITC } & \text { allyl isothiocyanate } \\ \text { b. w. } & \text { body weight } \\ \text { BSA } & \text { bovine serum albumin } \\ \text { CHL } & \text { cholesterol } \\ \text { FFA } & \text { free fatty acids } \\ \text { GLS } & \text { glucosinolates } \\ \text { HDL } & \text { high density lipoproteins } \\ \text { IC } & \text { half maximal inhibitory concentration } \\ \text { iNOS } & \text { inducible nitric oxide synthase } \\ \text { ITCs } & \text { isothiocyanates } \\ \text { LPL } & \text { lipoprotein lipase } \\ \text { NAC } & \text { N-acetylcysteine } \\ \text { NO } & \text { nitric oxide } \\ \text { SIN } & \text { sinigrin } \\ \text { TG } & \text { triacylglycerols }\end{array}$

\section{Introduction}

More and more investigations have been performed recently on plants in order to discover their possible anticancer properties. It 
has been estimated that diets rich in phytochemicals can significantly reduce cancer risk by as much as $20 \%$ [15]. Based on epidemiological observations, which correlated reduced incidence of cancer (particularly colon and rectal) in populations with intake of Brassicaceae family vegetables, biological studies have dealt with glucosinolates like sinigrin (SIN) and its hydrolysis product-allyl isothiocyanate (AITC). The conversion of SIN into AITC is catalyzed by myrosinase, a thioglucosidase (E.C. 3.2.3.1) after plant cellular damage or in the presence of gut microflora $[10,21]$.

Human exposure to these compounds is undoubtedly widespread and frequent, as many common cruciferous vegetables are a rich source of them (e.g. Brussels sprouts, red, Savoy, white cabbages, cauliflower, broccoli, condiments and salad crops) [38]. The content of SIN per $100 \mathrm{~g}$ fresh weight of appropriate vegetables is in Brussels sprouts (44.50 mg), Savoy cabbage (17.06 mg), white cabbage $(16.31 \mathrm{mg})$, red cabbage $(3.77 \mathrm{mg})$, kale $(12.47 \mathrm{mg})$, cauliflower (4.74 mg), and broccoli (0.19 mg) [38]. According to Steinbrecher and Linseisen [38] the mean total glucosinolate intake, for instance, in a German population ( \pm standard error) was $14.2( \pm 1.1) \mathrm{mg} /$ day for men and $14.8( \pm 1.3) \mathrm{mg} /$ day for women. However, allyl isothiocyanate may be present in following foods per $100 \mathrm{~g}$ : syrups $(1-8.8 \mathrm{mg})$, meats $(8.7 \mathrm{mg})$, condiments $(5.2 \mathrm{mg})$, baked goods $(0.52 \mathrm{mg})$, candies and ice cream $(0.05 \mathrm{mg})$ [24], mainly as a component in volatile oil of mustard, which is used in pickling spices (meat) and imitation pineapple flavouring (ice cream). Average human consumption of AITC has been estimated to be less than $1 \mathrm{mg} /$ day (approximately $10 \mu \mathrm{g} / \mathrm{kg}$ body weight) [20, 41].

Biological activity of SIN and AITC is wide. Although SIN itself is not known to possess antimicrobial properties, its hydrolysis product AITC kills bacteria and fungi. Herein, AITC action appears to resemble polymyxin $\mathrm{B}$, which is known to bind to cell membrane and to increase its permeability [25]. Also, insecticidal properties of these compounds have been reported [29]. AITC was also shown to significantly inhibit both thioredoxin reductase and acetate kinase at approximately $100 \mu \mathrm{M}$ [27], enzymes playing an important role in cell growth and proliferation. Although sinigrin itself is not known to show any antiproliferative activity, AITC inhibits proliferation of various types of human cancer cells, with the $\mathrm{IC}_{50}$ values at the low micromolar range. Inhibition of cell proliferation by AITC was associated with cell cycle arrest and/or induction of apoptosis [14]. What more, Hwang and Lee [18] reported that AITC and its NAC conjugate play important roles in cancer metastasis by inhibition of cell adhesion, migration and invasion. AITC was also found to significantly inhibit the production of nitric oxide (NO) and the expression of inducible nitric oxide synthase (iNOS) important signalling molecules in inflammation and cancer [19]. Additionally, AITC induces enzymes of xenobiotic metabolism in cell cultures and, when included in the diet, in the livers and peripheral organs of mice and rats [6]. AITC has been shown to induce several phase 2 enzymes including $\mathrm{NAD}[\mathrm{P}] \mathrm{H}$ :quinine oxidoreductase-1, glutathione S-transferase in both cultured cells in vitro and animal tissues in vivo [17, 30]. AITC also was found to significantly inhibit in a dosedependent manner the formation of gastric lesions induced by ethanol, hydrochloric acid, ammonia, aspirin and indomethacin in Sprague-Dawley rats at the oral dose levels of 1.25 $10 \mathrm{mg} / \mathrm{kg}$ b. w. (12.5-100 $\mu \mathrm{mol} / \mathrm{kg} \mathrm{b.} \mathrm{w.)} \mathrm{[28].} \mathrm{Nevertheless,}$ some data suggest cytotoxic and genotoxic properties of AITC. Allyl isothiocyanate significantly induced 8-oxodG formation in HL-60 cells, but not in $\mathrm{H}_{2} \mathrm{O}_{2}$-resistant HP100 cells, suggesting the involvement of $\mathrm{H}_{2} \mathrm{O}_{2}$ in cellular DNA damage [31]. Participation of reactive oxygen species in the genotoxic effect of AITC was also confirmed by the findings reported by Kassie and Knasmüller [20].

Summing up, many substances that occur naturally in food plant may modify, in significant way, the metabolic processes in their consumers. However, we still know very little about the metabolic effects of glucosinolates, particularly in relation to liver (function), where AITC was found in the greatest amounts [4]. There have been only a few studies conducted into the metabolism and biochemical activity of individual glucosinolates and their derivatives. It is known that AITC given in oral doses $(50 ; 100 ; 150 \mathrm{mg} / \mathrm{kg} \mathrm{b}$. w.) for only 3 consecutive days increased liver weight and serum aspartate aminotransferase activity [23]. So that, this result demonstrate that a high intake of this phytochemical instead of giving beneficial effects may produce negative results also on the metabolic pathways. As mentioned earlier, dietary consumption levels of SIN and AITC appear to be several orders of magnitude lower (approximately $150 \mu \mathrm{g} \mathrm{SIN} / \mathrm{kg} \mathrm{b.} \mathrm{w.} \mathrm{[38]}$ and $10 \mu \mathrm{g}$ AITC $/ \mathrm{kg} \mathrm{b}$. w. [41]) than the doses used in animal studies including the present one $(20 \mathrm{mg} \mathrm{SIN} / \mathrm{kg} \mathrm{b}$. w. and 2.5-5.0 mg AITC/kg b. w.). Since epidemiological data indicate that a diet rich in cruciferous vegetables can protect laboratory animals from tumorigenic effects of model carcinogens, overall intake of glucosinolates and their breakdown products in human diet is suggested to be increased (for example by genetic manipulation of plants or by artificial supplementation of the diet). In order to properly define the balance of benefit and risk of their high consumption, the SIN and AITC dose levels used in the preclinical studies, also in the present trial, are far greater than what humans are normally exposed to.

Taking into consideration the above-mentioned information, this research project aimed at expanding our knowledge about the influence of high SIN and AITC intake on carbohydrate and lipid parameters in a rat model at different time of their action and doses of SIN hydrolysis product in vivo and in vitro conditions. Time-related response of the analyzed compounds was included in this study in order to 
evaluate possible time-interval required for sinigrin decomposition as well as AITC metabolic effect intensification.

\section{Materials and Methods}

Rats in vivo trial were administrated SIN and AITC at appropriate animal doses, which had no impact on food consumption, rat weight, or general appearance and behaviour were used in such doses by many other researchers $[4,8,10$, $36,37]$. It was assumed that $1 \mathrm{~mol}$ of the isothiocyanate corresponds to $1 \mathrm{~mol}$ of its parent glucosinolate [38].

All chemicals including sinigrin and allyl isothiocyanate were purchased from Sigma Chemical (St. Louis, MO, USA).

The protocols of experiments were reviewed and approved by the Local Ethical Commission for Investigation on Animals.

\section{In Vivo Experiment}

\section{Animal Maintenance}

The research was conducted on 64 growing male Wistar rats with an initial body weight of $120 \pm 5 \mathrm{~g}$. Male Wistar rats were obtained from Brwinów (Poland). The animals were maintained under standard conditions of light $(12 \mathrm{~h})$ and temperature $\left(22 \pm 2^{\circ} \mathrm{C}\right)$ with free access to laboratory pellets and tap water. The rats were fed a complete laboratory diet ("Labofeed", Poland) containing in \%: crude protein 17, crude fat 3.5, crude fibre 7 and $12.15 \mathrm{MJ} / \mathrm{kg}$ net energy. The trial involved two separate experiments. Before the research, animals were divided into 8 groups $(n=8)$ for the two investigations (4 groups for each one). The first trial involved single oral administration of SIN or AITC at two different doses (groups II, III, IV, respectively). The second trial concerned SIN or AITC gavage for 14 days (groups VI, VII, VIII, respectively). Animals from groups I and V received water and served as controls. Rats from experimental groups II/VI, III/VII and IV/VIII were given intragastrically $50 \mu \mathrm{mol} / \mathrm{kg}$ b. w. sinigrin or $25 \mu \mathrm{mol} / \mathrm{kg}$ b. w. or $50 \mu \mathrm{mol} /$ $\mathrm{kg}$ b. w. allyl isothiocyanate, respectively. SIN and AITC were prepared by solution in distilled water and were given at a dose of $1 \mathrm{~mL} / 100 \mathrm{~g} \mathrm{~b}$. w. In the first experiment, the compounds were given once and after $4 \mathrm{~h}$ the animals were decapitated. In the second research, rats received the substances once a day as a single morning dose for 14 days and the animals were decapitated $4 \mathrm{~h}$ after the last intragastric treatment and their blood and liver were sampled.

Measurement of Carbohydrate and Lipid Parameters

The serum was used for the determination of blood insulin, glucose, free fatty acids (FFA), phospholipids, triacylglycer- ols (TG) and total, free, esterified cholesterol (CHL) and total cholesterol in high-density lipoproteins (HDL). In the liver, cholesterol, triacylglycerols and glycogen were determined.

Insulin was assayed radioimmunologically by using the kit specific for rat hormone (Linco Research, St. Charles, MO, USA).

Glucose was colorimetrically assayed by the enzymatic method with glucose oxidase, peroxidase and o-dianisidine [16]. Free fatty acids were determined according to Duncombe [9] and triacylglyceroles were assayed by the method of Foster and Dunn [12]. Total, free and esterified cholesterol levels as well as cholesterol in HDL were measured by the enzymatic method of Richmond [34]. High-density lipoproteins were obtained from blood serum after precipitation of lipoproteins other than HDL using polyethylene glycol 6000 according to Demacker et al. [7]. Phospholipids were determined enzymatically with a kit provided by BioMerieux (France). Liver cholesterol was assayed after extraction of lipids [11] and evaporation of the extract [34]. The amount of liver glycogen was determined after extraction in $30 \% \mathrm{KOH}$ and hydrolysis with amyloglucosidase. Liver triacylglycerols were assayed after extraction [11].

\section{In Vitro Experiment}

\section{Preparation of Adipocytes}

After 7 days of adaptation, the male rats weighing $160 \pm 5 \mathrm{~g}$ were sacrificed by decapitation and the epididymal adipose tissue was taken. Adipocytes were isolated according to the method of Rodbell [35] with minor modifications [39]. The fat tissue removed from 10 rats was pooled, rinsed with saline, cut with scissors and placed in a plastic flask containing Krebs-Ringer buffer $(118 \mathrm{mM} \mathrm{NaCl}, 4.8 \mathrm{mM}$ $\mathrm{KCl}, 1.3 \mathrm{mM} \mathrm{CaCl}_{2}, 1.2 \mathrm{mM} \mathrm{KH_{2 }} \mathrm{PO}_{4}, 1.2 \mathrm{mM} \mathrm{MgSO}_{4}$, $24.8 \mathrm{mM} \mathrm{NaHCO}_{3}$ ) with $3 \mathrm{mM}$ glucose, $3 \%$ bovine serum albumin (BSA, fraction V), $10 \mathrm{mM}$ HEPES and $2 \mathrm{mg} / \mathrm{mL}$ collagenase (EC 3.4.24.3. from Clostridium histolyticum, type II). Incubation was performed for $90 \mathrm{~min}$ by shaking at $37^{\circ} \mathrm{C}$. Isolated adipocytes after incubation were rinsed 4 times with warm $\left(37^{\circ} \mathrm{C}\right)$ Krebs-Ringer buffer without collagenase, filtered through nylon mesh and counted under the microscope with a Bürker-Türk counting chamber. Cells viability was about $95 \%$ as determined by trypan blue exclusion.

\section{Lipolysis}

Fat cell suspensions $\left(10^{6}\right.$ cells $\left./ \mathrm{mL}\right)$ were incubated in plastic tubes at $37{ }^{\circ} \mathrm{C}$ for $90 \mathrm{~min}$ with the Krebs-Ringer buffer containing $3 \mathrm{mM}$ glucose, $10 \mathrm{mM}$ HEPES and $3 \%$ $\mathrm{BSA}$ in the absence or the presence of $1 \mu \mathrm{M}$ epinephrine. The examined AITC was dissolved in DMSO and $10 \mu \mathrm{L}$ of 
this solution (or DMSO alone in the case of control tubes) was added to $990 \mu \mathrm{L}$ of the buffer with adipocytes. The final concentrations of AITC were $1 \mu \mathrm{M}, 10 \mu \mathrm{M}$ and $100 \mu \mathrm{M}$. Each experiment was performed three times with five replicates. The glycerol released from adipocytes, reflecting the intensity of lipolysis, was measured using the method of Foster and Dunn [12].

\section{Statistical Analysis}

The results were evaluated statistically using one-way analysis of variance (ANOVA) and Duncan's multiple range test at $p \leq 0.05$.

\section{Results}

Effects of SIN and AITC on Carbohydrate and Lipid Metabolism In Vivo

In the short term trial $(4 \mathrm{~h})$, the only metabolic changes were observed after AITC administration. The single treatment of allyl isothiocyanate caused increment of glycaemia (34.1\%) at higher dose and liver triacylglycerols at both doses $(40.6 \%$ and $40.2 \%$, respectively). On the other hand, both compounds failed to affect the blood serum insulin, free fatty acids, phospholipids, triacylglycerols, total, free and sterified cholesterol, HDL-cholesterol concentrations, and cholesterol and glycogen contents in the liver (Table 1).

Surprisingly, the 2 weeks experiment brought many significant metabolic changes caused by AITC as well as SIN. In addition, the same mode of metabolic pathway action was observed after administration of both compounds. These changes concerned the alteration of blood serum parameters: FFA, esterified CHL, total CHL and TG. As a consequence of their ingestion, the concentration of FFA, esterified CHL and total CHL was significantly elevated, whereas TG were reduced. A very strong FFA increase was worth nothing $\left(\mathrm{SIN}_{50} 138.5 \%\right.$; $\mathrm{AITC}_{25} 161.5 \%$; $\mathrm{AITC}_{50}$ 130.7\%). Additionally, AITC at both doses caused considerable increase in the serum insulin concentration $\left(\mathrm{AITC}_{25}\right.$ $63.2 \%$; $\mathrm{AITC}_{50} 25.0 \%$ ) as well as glycogen content in the liver $\left(\mathrm{AITC}_{25}\right.$ 28.4\%; $\mathrm{AITC}_{50}$ 54.1\%). Sinigrin showed lack of essential influence on alteration of pancreatic hormone concentration and enhanced glycogen generation, though general increasing tendency to glycogen formation was maintained also after SIN ingestion (Table 1).

Effect of Allyl Isothiocyanate $(1 \mu \mathrm{M}, 10 \mu \mathrm{M}, 100 \mu \mathrm{M})$ on Basal Lipolysis In Vitro Experiment

AITC showed a dose-dependent enhanced effect on basal lipolysis. AITC strongly elevated basal lipolysis by $74.2 \%$ only at $10 \mu \mathrm{M}$ dose in comparison with the control. Release of glycerol to the incubation buffer reflecting lipolysis remained unchanged at $1 \mu \mathrm{M}$ and $100 \mu \mathrm{M}$ AITC dose (Fig 1).

Effect of Allyl Isothiocyanate $(1 \mu \mathrm{M}, 10 \mu \mathrm{M}, 100 \mu \mathrm{M})$ on Lipolysis Stimulated by Epinephrine $(1 \mu \mathrm{M})$ In Vitro Experiment

The epinephrine-induced lipolysis was dependent on AITC concentration and its stimulatory or inhibitory influence was observed. Lipolysis induced by $1 \mu \mathrm{M}$ epinephrine was significantly enhanced by AITC at $1 \mu \mathrm{M}(16.3 \%)$, although AITC at this dose was not able to stimulate basal lipolysis. AITC at the dose $10 \mu \mathrm{M}$ revealed universal ability inducing the mentioned basal triacylglycerols decomposition as well as lipolysis in the presence of epinephrine $(16.9 \%)$. However, in the presence of $100 \mu \mathrm{M}$ AITC epinephrineinduced lipolysis was clearly decreased, where the $18.6 \%$ drop of glycerol release was noted in comparison with the control (Fig. 2).

\section{Discussion}

The result of our trials, following different duration of SIN and AITC ingestion shows that SIN degradation product allyl isothiocyanate absorbed from gastrointenstinal track quickly and revealed high biological activity on biochemical parameters. This result is in good agreement with other reports showing that the bioavailability of AITC is extremely high, as nearly $90 \%$ of orally administered AITC is absorbed [41]. Pharmacokinetic studies using orally administered isothiocyanates proved that sole glucosinolates degradation products like ITCs undergo rapid absorption from the upper gastrointestinal tract. The rate of appearance of ${ }^{14} \mathrm{C}$ in the blood after dosing rats with $\left[{ }^{14} \mathrm{C}\right]$ allyl isothiocyanate $(25$ to $250 \mu \mathrm{mol} / \mathrm{kg}$ ) is rapid, with a peak concentration of 10 to $100 \mu \mathrm{M}$ occurring at $3 \mathrm{~h}$ [4]. If it pertains to SIN according to Rabot et al. [33] only about $7 \%$ sinigrin can be absorbed from intestinal mucosa; however, it possesses limited biological activity. In treated rats with $50 \mu \mathrm{mol} \mathrm{SIN}$, the highest recovery of intact sinigrin in the gastrointestinal tract averaged $28 \mu \mathrm{mol} 3 \mathrm{~h}$ after gavage. The largest amount, accounting for $46 \%$ of the ingested dose, was present in the caecum and colon [10]. These data could explain why, in the present 4-hour trial, metabolic changes were observed only after AITC administration. Higher dose of AITC caused glycaemia, whereas both AITC doses led to liver triacylglycerols gain. Such mode of action in the liver after isothiocyanate ingestion was achieved in the author's former research after $4 \mathrm{~h}$ administration of other glucosinolate degradation product like phenethyl isothiocyanate derived from gluconasturtiin [32]. The effect of accumulation of TG in 
Table 1 The effect of oral administration of sinigrin and allyl isothiocyanate on some metabolic parameters in the blood serum and the liver after different time of their action

\begin{tabular}{|c|c|c|c|c|}
\hline Parameters in the blood serum and the liver & Control & $\mathrm{SIN}_{50}$ & $\mathrm{AITC}_{25}$ & $\mathrm{AITC}_{50}$ \\
\hline \multicolumn{5}{|l|}{ After 4 hours } \\
\hline Glucose $(\mathrm{mmol} / \mathrm{L})$ & $3.40 \pm 0.31^{\mathrm{a}}$ & $3.70 \pm 0.21^{\mathrm{ab}}$ & $3.87 \pm 0.16^{\mathrm{ab}}$ & $4.56 \pm 0.16^{b}$ \\
\hline Insulin $(\mathrm{ng} / \mathrm{mL})$ & $1.78 \pm 0.21$ & $1.52 \pm 0.03$ & $1.66 \pm 0.10$ & $1.60 \pm 0.08$ \\
\hline Free fatty acids $(\mathrm{mmol} / \mathrm{L})$ & $0.45 \pm 0.11$ & $0.42 \pm 0.03$ & $0.32 \pm 0.03$ & $0.37 \pm 0.04$ \\
\hline Phospholipids (mmol/L) & $1.90 \pm 0.19$ & $1.95 \pm 0.12$ & $2.15 \pm 0.17$ & $1.79 \pm 0.16$ \\
\hline Triacylglycerols (mmol/L) & $1.18 \pm 0.26$ & $1.66 \pm 0.49$ & $1.46 \pm 0.26$ & $0.89 \pm 0.10$ \\
\hline Total cholesterol (mmol/L) & $0.84 \pm 0.03$ & $0.91 \pm 0.03$ & $0.97 \pm 0.08$ & $0.90 \pm 0.09$ \\
\hline Free cholesterol $(\mathrm{mmol} / \mathrm{L})$ & $0.35 \pm 0.03$ & $0.42 \pm 0.04$ & $0.40 \pm 0.04$ & $0.38 \pm 0.06$ \\
\hline Esterified cholesterol (mmol/L) & $0.48 \pm 0.02$ & $0.50 \pm 0.04$ & $0.57 \pm 0.05$ & $0.53 \pm 0.03$ \\
\hline HDL-cholesterol (mmol/L) & $0.69 \pm 0.06$ & $0.70 \pm 0.04$ & $0.81 \pm 0.09$ & $0.74 \pm 0.15$ \\
\hline Liver cholesterol (mg/g WT) & $1.23 \pm 0.05$ & $1.29 \pm 0.01$ & $1.16 \pm 0.02$ & $1.25 \pm 0.04$ \\
\hline Liver Triacylglycerols (mg/g WT) & $11.53 \pm 2.26^{\mathrm{a}}$ & $15.49 \pm 0.59^{\mathrm{ab}}$ & $16.21 \pm 1.51^{\mathrm{b}}$ & $16.16 \pm 0.68^{b}$ \\
\hline Liver glycogen (mg/g WT) & $31.50 \pm 6.77$ & $41.20 \pm 4.10$ & $37.23 \pm 2.66$ & $33.02 \pm 2.44$ \\
\hline \multicolumn{5}{|l|}{ After 2 weeks } \\
\hline Glucose $(\mathrm{mmol} / \mathrm{L})$ & $5.27 \pm 0.22$ & $5.07 \pm 0.17$ & $5.23 \pm 0.17$ & $5.45 \pm 0.13$ \\
\hline Insulin $(\mathrm{ng} / \mathrm{mL})$ & $1.52 \pm 0.27^{\mathrm{a}}$ & $1.41 \pm 0.18^{\mathrm{ab}}$ & $2.48 \pm 0.60^{b}$ & $1.90 \pm 0.32^{b}$ \\
\hline Free fatty acids $(\mathrm{mmol} / \mathrm{L})$ & $0.26 \pm 0.01^{\mathrm{a}}$ & $0.62 \pm 0.03^{b}$ & $0.68 \pm 0.05^{b}$ & $0.60 \pm 0.05^{b}$ \\
\hline Phospholipids (mmol/L) & $0.89 \pm 0.04$ & $0.96 \pm 0.04$ & $1.00 \pm 0.04$ & $0.97 \pm 0.07$ \\
\hline Triacylglycerols (mmol/L) & $0.88 \pm 0.05^{\mathrm{a}}$ & $0.54 \pm 0.02^{b}$ & $0.60 \pm 0.03^{b}$ & $0.76 \pm 0.05^{b}$ \\
\hline Total cholesterol $(\mathrm{mmol} / \mathrm{L})$ & $0.87 \pm 0.02^{\mathrm{a}}$ & $1.12 \pm 0.03^{\mathrm{b}}$ & $1.09 \pm 0.05^{\mathrm{b}}$ & $1.05 \pm 0.07^{\mathrm{b}}$ \\
\hline Free cholesterol (mmol/L) & $0.30 \pm 0.02$ & $0.28 \pm 0.02$ & $0.34 \pm 0.04$ & $0.29 \pm 0.04$ \\
\hline Esterified cholesterol $(\mathrm{mmol} / \mathrm{L})$ & $0.57 \pm 0.01^{\mathrm{a}}$ & $0.85 \pm 0.02^{b}$ & $0.76 \pm 0.02^{b}$ & $0.78 \pm 0.04^{b}$ \\
\hline HDL-cholesterol (mmol/L) & $0.60 \pm 0.02$ & $0.74 \pm 0.04$ & $0.68 \pm 0.05$ & $0.63 \pm 0.05$ \\
\hline Liver cholesterol (mg/g WT) & $2.11 \pm 0.04$ & $2.19 \pm 0.08$ & $2.13 \pm 0.09$ & $2.29 \pm 0.07$ \\
\hline Liver Triacylglycerols (mg/g WT) & $15.73 \pm 0.70$ & $17.02 \pm 1.05$ & $18.93 \pm 2.45$ & $15.31 \pm 1.39$ \\
\hline Liver glycogen (mg/g WT) & $45.00 \pm 0.60^{\mathrm{a}}$ & $52.30 \pm 2.63^{\mathrm{abc}}$ & $57.80 \pm 3.19^{\mathrm{b}}$ & $69.35 \pm 4.33^{\mathrm{c}}$ \\
\hline
\end{tabular}

Values are means \pm SEM for eight animals. Means in rows with different superscript letters are statistically different $(p \leq 0.05)$. Sinigrin at the dose $50 \mu \mathrm{mol} / \mathrm{kg}$ b. w. $\left(\mathrm{SIN}_{50}\right)$, allyl isothiocyanate $25 \mu \mathrm{mol} / \mathrm{kg} \mathrm{b}$. w. $\left(\mathrm{AITC}_{25}\right)$ or $50 \mu \mathrm{mol} / \mathrm{kg} \mathrm{b}$. w. (AITC $\left.\mathrm{AI}_{50}\right)$ were given intragastrically

b. $w$. body weight, $W T$ wet tissue

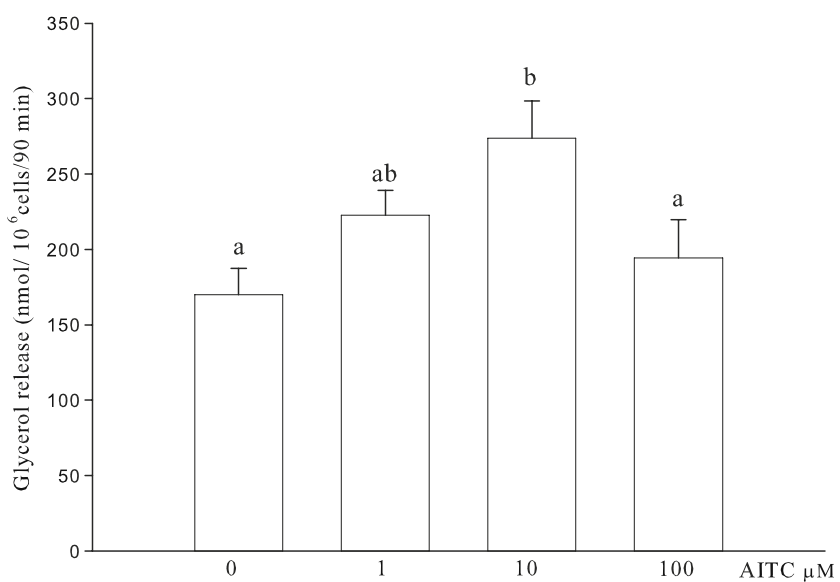

Fig. 1 The effect of allyl isothiocyanate on basal lipolysis in isolated rat adipocytes. Each column represents the mean \pm SEM for five repetitions $(n=5)$. Mean values marked by different superscript letters differ statistically $(p \leq 0.05)$.

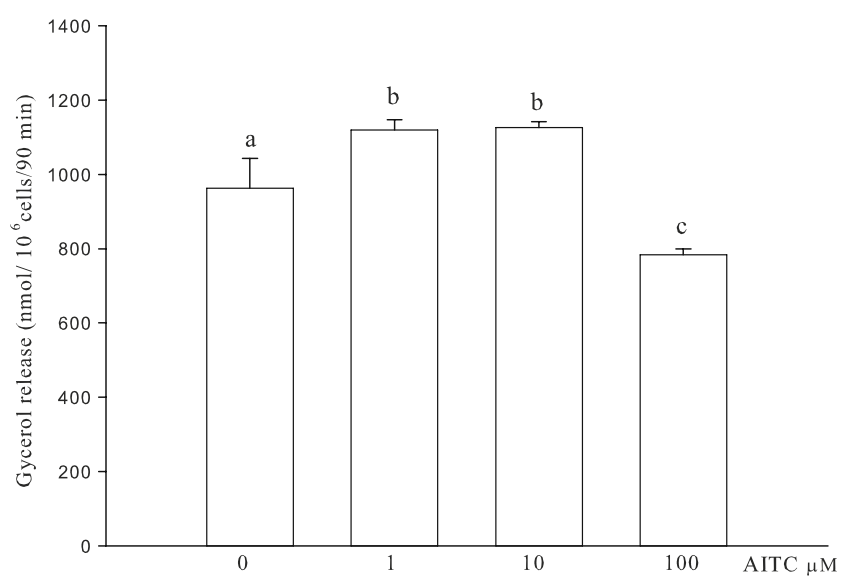

Fig. 2 The effect of allyl isothiocyanate on lipolysis stimulated by epinephrine $(1 \mu \mathrm{M})$ in isolated rat adipocytes. Each column represents the mean \pm SEM for five repetitions $(n=5)$. Mean values marked by different superscript letters differ statistically $(p \leq 0.05)$. 
the liver may be a result of its enhanced synthesis or/and inhibited utilization by enhanced transfer to a liver cytosolic storage pool. Higher AITC dose caused additionally a distinct blood glucose concentration increase. Because liver glycogen drop with simultaneous insulin elevation was not noted, the disturbed facilitation of glucose entry into muscle, adipose and other tissues could not be excluded after AITC short term trial.

The obtained results from long term action of sinigrin administration may suggest, indirectly, bioconversion of that parent glucosinolate mainly to allyl isothiocyanate because the same mode of metabolic pathway action was observed after SIN as well as AITC administration (the same alteration of FFA, TG, esterified CHL, total CHL in the serum). It has been recently ascertained that the ability to degrade glucosinolates is widely distributed among intestinal flora, which may be the source of enzymes exhibiting the ability to hydrolyze GLS into isothiocyanates [13]. Elfoul et al. [10] showed that AITC appeared in the gastrointestinal tract as soon as $3 \mathrm{~h}$ after $50 \mu \mathrm{mol}$ SIN gavage, but its substantial amounts, up to $100 \mathrm{nmol}$, were observed really between $9 \mathrm{~h}$ and $12 \mathrm{~h}$ in the caecal and colonic contents of gnotobiotic rats harbouring a human digestive strain of Bacteroides thetaiotaomicron. Such results were achieved also by Krul et al. [21] investigating the microbial metabolism of glucosinolates in dynamic in vitro large-intestinal model, closely resembling the human colon. The same alteration in carbohydrate and lipid parameters after long term action of sinigrin as well as allyl isothiocyanate once again confirmed the general observation (agreement) that ITCs are active derivatives of GLS, and the biological activity of the latter depends on the time that related endogenous processes degrade GLS to corresponding ITCs.

In vivo, isothiocyanates are conjugated with glutathione and then sequentially metabolized to mercapturic acids (dithiocarbamates), which undergo the renal excretion [36]. The obtained metabolic changes in liver and serum in the present trial showed that besides the mercapturic acid pathway, isothiocyanates may follow enterohepatic circulation. In rats dosed with $\left({ }^{14} \mathrm{C}\right)$ allyl isothiocyanate, the higher value for biliary excretion confirms that some material undergoes such routes of metabolism. In tissues, the greatest amounts of radioactivity are retained in the liver, kidneys and intestinal mucosa [4]. This enterohepatic circulation of allyl isothiocyanate may exert in this way an impact on some intestinal and/or liver enzymes. It is highly probable that the noted elevation of esterified cholesterol was caused by intensified cholesterol esterification by putative AITC influence on acyl-CoA:cholesterol acyltransferase (ACAT; EC 2.3.1.26) activity. ACAT activation in the intestinal cells and/or the liver enhances the uptake of intestinal cholesterol and/or the incorporation of hepatic cholesterol into lipoproteins resulting in elevation of total serum cholesterol [5].
Enhancement of total serum cholesterol observed also in the performed trial could additionally prove this presumption. Because the content of liver cholesterol was unchanged, it seems that AITC influenced only the activity of ACAT in intestinal cells and exerted no impact on liver ACAT. A TG drop was also observed with concomitant exceptionally distinct FFA enhancement in the serum (more than 100\%). Because of the above-mentioned enterohepatic circulation of allyl isothiocyanate, it is quite possible that its presence limited chylomicrones synthesis in the intestine and led to the TG drop. However, it may be also amplified by enhancement of lipoprotein lipase activity (LPL; EC 3.1.1.34), which is a critical step in clearance of plasma TG, highly regulated by nutritional and hormonal status. In mammals, the main modulator of LPL is insulin [1]. Enhancement of this hormone in the present research could additionally confirm this assumption. Nevertheless, it is commonly known that the serum FFA are derived mainly from adipose tissue. The elevated supply of fatty acids to circulation by putative action of AITC on adipocytes is proved by the present experiment in vitro where AITC potentiated basal lipolysis process at $10 \mu \mathrm{M}$. Such AITC concentration in the blood is achieved after dosing rats with $25-50 \mu \mathrm{mol} / \mathrm{kg}$ allyl isothiocyanate [4], the doses also used in the present research in vivo. Results of this study revealed also enhanced lipolytic response to epinephrine in adipocytes exposed to $1 \mu \mathrm{M}$ and $10 \mu \mathrm{M}$ AITC. Because AITC at $1 \mu \mathrm{M}$ failed to rise basal glycerol release, this result indicates rather synergistic than additive action with the lipolytic hormone at this dose, amplifying epinephrine effect. The potentiatory effect of AITC on epinephrine-induced lipolysis seems to result, at least partially, from increased cAMP in fat cells, which is crucial for the stimulation of lipolysis [26]. In reverse, action at $10 \mu \mathrm{M}$ AITC seems to be additive, since this dose was also able to stimulate basal lipolysis. What is interesting, $100 \mu \mathrm{M}$ AITC strongly attenuated epinephrine signaling pathway and had no effect on basal lipolysis. The stimulation of basal lipolysis and AITC influence on epinephrine activity probably depends on many factors, certainly, on its dose.

Because both AITC doses stimulated significant insulin secretion without any rise in blood glucose concentration, a direct AITC influence not only on liver and intestine, but also on pancreas can be suggested. This organ previously was shown to be affected by glucosinolate breakdown derivatives [40]. It is not also possible to exclude indirect AITC action on this organ by the above-mentioned excessive release of FFA from adipose tissue. According to Boden [3], acute increases in plasma levels of long-chain fatty acids can raise plasma insulin levels by stimulating insulin secretion or by decreasing insulin clearance. Surprisingly, such effect was not noted after sinigrin administration. However, it is known that the hydrolysis of sinigrin leads to the formation, apart from allyl 
isothiocyanates, also thiocyanides and nitriles, the latter of which are the most toxic hydrolysis products of glucosinolates in natural environments [2]. Those degradation products could attenuate the AITC action on insulin elevation. Therefore, the influence of additional sinigrin degradation products could also mitigate significantly the enhancement of liver glycogen content, which was observed after gavage of two doses of AITC, which stimulates glucose uptake indirectly by increased insulin secretion from pancreas. Despite this action, surprisingly, the blood serum glucose level was unchanged. This phenomenon could be explained, once again, by the observed exceptionally high FFA levels in this research. As indicated by other researchers [22], elevated serum FFA increase hepatic gluconeogenesis as well as reduce the ability of insulin to suppress this process in the liver, balancing the serum glucose concentration.

To conclude, the results of this study demonstrate that AITC is an active derivative of SIN, and the biological activity of the latter depends on the time that related endogenous processes degrade sinigrin to corresponding allyl isothiocyanate. The metabolic effect of AITC is multidirectional, indicating its impact on many organs like liver as well as pancreas, intestine in vivo action and rat adipocytes in vitro. Unfortunately, its influence is adverse for the majority of metabolic pathways of carbohydrates and lipids in rat model and potentiated with the time of its action. AITC, independently of dose and time, disturbed liver homeostasis. Elongated time of its activity changes the end-product in liver served as energy storage from triacylglycerols into glycogen. Short AITC action, except for steatosis, enhanced glycaemia (at higher dose). Long AITC treatment intensified liver glycogen store as a consequence of noted insulinaemia (action on pancreas), and with SIN evoked cholesterolaemia (action on intestine) and serum FFA increase (action on fat cells). Beneficial sides of their activity concerned triacylglycerols drop in the blood serum. AITC can augment basal and epinephrine-induced lipolysis; however, the stimulation of basal lipolysis and the AITC influence on epinephrine action seems to be dependent on many factors, certainly, on its dose. It would be urged that any further increase (abuse?) in dietary SIN and AITC should be also preceded by thorough and comprehensive investigations of their metabolic action.

Acknowledgments The author would like to thank dr. K. Szkudelska for her help during the performance of in vitro experiment.

Open Access This article is distributed under the terms of the Creative Commons Attribution Noncommercial License which permits any noncommercial use, distribution, and reproduction in any medium, provided the original author(s) and source are credited.

\section{References}

1. Albalat A, Saera-Vila A, Capilla E, Gutierrez J, Perez-Sanchez J, Navarro I (2007) Insulin regulation of lipoprotein lipase (LPL) activity and expression in gilthead sea bream (Sparus aurata). Comp Biochem Physiol 148:151-159

2. Barrett JE, Klopfenstein CF, Leipold HW (1998) Alkaline heating of canola and rapeseed meals reduces toxicity for chicks. Plant Foods Hum Nutr 52:9-15

3. Boden G (2005) Free fatty acids and insulin secretion in humans. Curr Diab Rep 5(3):167-170

4. Bollard M, Stribbling S, Mitchell S, Caldwell J (1997) The disposition of allyl isothiocyanate in the rat and mouse. Food Chem Toxicol 35:933-943

5. Buhman KK, Chen HC, Farese RV Jr (2001) The enzymes of neutral lipid synthesis. J Biol Chem 276:40369-40372

6. Conaway CC, Yang YM, Chung FL (2002) Isothiocyanates as cancer chemo-preventive agents: their biological activities and metabolism in rodents and humans. Curr Drug Metab 3:233-255

7. Demacker PN, Hijmans AG, Vos-Janssen HE, van't Laar A, Jansen AP (1980) A study of the use of polyethylene glycol in estimating cholesterol in high-density lipoprotein. Clin Chem 26:1775-1779

8. Duncan AJ, Rabot S, Nugon-Baudon L (1997) Urinary mercapturic acids as markers for the determination of isothiocyanate release from glucosinolates in rats fed a caulifower diet. J Sci Food Agric 73:214-220

9. Duncombe D (1964) The colorimetric micro-determination of nonesterified fatty acids in plasma. Clin Chim Acta 9:122-125

10. Elfoul L, Rabot S, Khelifa N, Quinsac A, Duguay A, Rimbault A (2001) Formation of allyl isothiocyanate from sinigrin in the digestive tract of rats monoassociated with a human colonic strain of Bacteroides thetaiotaomicron. FEMS Microbiol Lett 197:99103

11. Folch J, Lees M, Sloane GSH (1975) A simple method of the isolation and purification of total lipids from animal tissues. J Biol Chem 226:497-509

12. Foster LB, Dunn RT (1973) Stable reagents for determination of serum triglycerides by a colorimetric Hatzsch condensation method. Clin Chem 19:338-340

13. Getahun SM, Chung FL (1999) Conversion of glucosinolates to isothiocyanates in humans after ingestion of cooked watercress. Cancer Epidemiol Biomark Prev 8:447-451

14. Hecht SS (2000) Inhibition of carcinogenesis by isothiocyanates. Drug Metab Rev 32:395-411

15. Heo BG, Chon SU, Park YJ, Bae JH, Park SM, Park YS, Jang HG, Gorinstein S (2009) Antiproliferative activity of Korean wild vegetables on different human tumor cell lines. Plant Foods Hum Nutr 64:257-263

16. Hugget ASG, Nixon DA (1957) Use of glucose-oxidase, peroxidase and o-dianisidine in determination of blood and urinary glucose. Lancet 2:368-370

17. Hwang E, Lee HJ (2006) Induction of quinine reductase by allyl isothiocyanate (AITC) and the N-acetylcysteine conjugate of AITC in Hepa1c1c7 mouse hepatoma cells. Biofactors 26:7-15

18. Hwang E-S, Lee HJ (2006) Allyl isothiocyanate and its nacetylcysteine conjugate suppress metastasis via inhibition of invasion, migration, and matrix metalloproteinase-2/-9 activities in SK-Hep 1 human hepatoma cells. Exp Biol Med 231:421-430

19. Ippoushi K, Takeuchi A, Azuma K (2010) Sinigrin suppresses nitric oxide production in rats administered intraperitoneally with lipopolysaccharide. Food Chem 120:1119-1121

20. Kassie F, Knasmüller S (2000) Genotoxic effects of allyl isothiocyanate (AITC) and phenethyl isothiocyanate (PEITC). Chem Biol Interact 127:163-180 
21. Krul C, Humblot C, Philippe C, Vermeulen M, van Nuenen M, Havenaar R, Rabot S (2002) Metabolism of sinigrin (2-propenyl glucosinolate) by the human colonic microflora in a dynamic in vitro large-intenstinal model. Carcinogenesis 23:1009-1016

22. Lam TKT, Carpentier A, Lewis GF, Werve G, Fantus IG, Giacca A (2003) Mechanism of the free fatty acid-induced increase in hepatic glucose production. Am J Physiol Metab 284:863-873

23. Lewerenz H, Plass R, Macholz R (1988) Effect of allyl isothiocyanate on hepatic monooxygenases and serum transferases in rats. Toxicol Lett 44:65-70

24. Life Sciences Research Office (1975) Evaluation of the health aspects of mustard and oil of mustard as food ingredients. Bethesda, MD:Life Sciences Research Office. SCOGS16

25. Lin CM, Preston JF 3rd, Wei CI (2000) Antibacterial mechanism of allyl isothiocyanate. J Food Prot 63:727-734

26. Londos C, Brasaemle DL, Schultz CJ, Adler-Wailes DC, Levin DM, Kimmel AR, Rondinone CM (1999) On the control of lipolysis in adipocytes. Ann NY Acad Sci 892:155-168

27. Luciano FB, Hosseinian FS, Beta T, Holley RA (2008) Effect of free-SH containing compounds on allyl isothiocyanate antimicrobial activity against Escherichia coli O157:H7. J Food Sci 73: M214-M220

28. Matsuda H, Ochi M, Nagatomo A, Yoshikawa M (2007) Effects of allyl isothiocyanate from horseradish on several experimental gastric lesions in rat. Eur J Pharmacol 561:172-181

29. Mithen R (1992) Leaf glucosinolate profiles and their relationship to pest and desease resistance in oilseed rape. Euphytica 63:71-83

30. Munday R, Munday CM (2002) Selective induction of phase II enzymes in the urinary bladder of rats by allyl isothiocyanate, a compound derived from Brassica vegetables. Nutr Cancer 44:52-59

31. Murata M, Yamashita N, Inoue S, Kawanishi S (2000) Mechanism of oxidative DNA damage induced by carcinogenic allyl isothiocyanate. Free Radic Biol Med 28:797-805
32. Okulicz M, Bialik I, Chichłowska J (2005) The time-dependent effect of gluconasturtiin and phenethyl isothiocyanate on metabolic and antioxidative parameters in rats. J Anim Physiol Anim Nutr 89:367-372

33. Rabot S, Guerin C, Nugon-Baudon L, Szylit O (1995) Glucosinolate degradation by bacterial strains isolated from a human intestinal microflora. Proc 9th International Rapeseed Congress $1: 212-214$

34. Richmond W (1973) Preparation and properties of a cholesterol oxidase from Nocardia sp. and its application to the enzymatic assay of total cholesterol in serum. Clin Chem 19:1350-1356

35. Rodbell M (1963) Metabolism of isolated fat cells. J Biol Chem 239:375-380

36. Shapiro TA, Fahey JW, Wade KL, Stephenson KK, Talalay P (1998) Human metabolism and excretion of cancer chemoprotective glucosinolates and isothiocyanates of cruciferous vegetables. Cancer Epidemiol Biomark Prev 7:1091-1100

37. Shapiro TA, Fahey JW, Wade KL, Stephenson KK, Talalay P (2001) Chemoprotective glucosinolates and isothiocyanates of broccoli sprouts. Cancer Epidemiol Biomark Prev 10:501-508

38. Steinbrecher A, Linseisen J (2009) Dietary intake of individual glucosinolates in participants of the EPIC-Heidelberg Cohort Study. Ann Nutr Metab 54:87-96

39. Szkudelska K, Nogowski L, Szkudelski T (2000) Genistein affects lipogenesis and lipolysis in isolated rat adipocytes. J Steroid Biochem Mol Biol 75:265-271

40. Wallig MA, Kingston S, Staack R, Jeffery EH (1998) Induction of rat pancreatic glutathione S-transferase and quinone reductase activities by a mixture of glucosinolate breakdown derivatives found in Brussels Sprouts. Food Chem Toxicol $36: 365-373$

41. Zhang Y (2009) Allyl isothiocyanate as a cancer chemopreventive phytochemical. Mol Nutr Food Res 54:1-9 